\title{
State-Trait Anxiety Inventory
}

National Cancer Institute

\section{Source}

National Cancer Institute. State-Trait Anxiety Inventory. NCI Thesaurus. Code C95491.

An instrument for measuring anxiety. It is designed to differentiate between temporary

"state anxiety" and general, long-standing "trait anxiety". (Copyright Mind Garden, Inc.) 